\title{
Application of the Bivariate Calibration for Simultaneous Determinations of Hydrochlorothiazide/Enalapril Maleate and Hydrochlorothiazide/Bisoprolol Fumarate in Drug Tablets
}

\author{
Fadel Wedian ${ }^{1} \&$ Anas Lataifeh ${ }^{1}$ \\ ${ }^{1}$ Department of Chemistry, Tafila Technical University, Tafila, Jordan \\ Correspondence: Fadel Wedian, Department of Chemistry, Tafila Technical University, Tafila 66110, Jordan. \\ Tel: 962-77-657-9521.E-mail: alwedfad@yahoo.com
}

Received: February 19, 2013 Accepted: March 25, 2013 Online Published: April 16, 2013

doi:10.5539/ijc.v5n2p29 URL: http://dx.doi.org/10.5539/ijc.v5n2p29

\begin{abstract}
The bivariate calibration method was used for quantification of hydrochlorothiazide/enalapril maleate and hydrochlorothiazide/bisoprolol fumarate in pharmaceutical tablets. The determination of hydrochlorothiazide /enalapril maleate is made using new absorption wavelengths at 211 and $272 \mathrm{~nm}$, while hydrochlorothiazide/ bisoprolol fumarate is made at new wavelengths 273.5 and $293 \mathrm{~nm}$. The results are compared favorably to those obtained from HPLC. The method is simple, time saving, and costly effective; it could be used to determine the pharmaceutical compounds in commercial available products.
\end{abstract}

Keywords: hydrochlorothiazide, enalapril maleate, bisoprolol fumarate, bivariate calibration, drug tablets

\section{Introduction}

Angiozide $^{\circledR}$ and $\mathrm{Ziac}^{\circledR}$ are both formulated to treat hypertension in the form of tablets. The two drugs contain hydrochlorothiazide (HCT) at various proportions. HCT is a very effective thiazide diuretic. HCT is 6-chloro-1,1-dioxo-3,4-dihydro-2H-1,2,4-benzothiadiazine-7-sulfonamide, Figure 1 In addition, Angiozide ${ }^{\circledR}$ contains enalapril (EN) maleate salt, EN is (S)-1-((S)-2-((S)-1-ethoxy-1-oxo-4-phenylbutan-2ylamino)propanoyl)pyrrolidine-2-carboxylic acid, Figure 1, which is known to treat hypertension and congestive heart failure.

$\mathrm{Ziac}^{\circledR}$ contains Bisoprolol (BIS) Fumarate salt, BIS is a well known beta blocker. It is used treat cardiac arrhythmias and hypertension. BIS is 2-Propanol-1-[4-[[2-(1-methylethoxy)ethoxy]methyl]phenoxy]-3[(1-methylethyl)amino], Figure 1.

Simultaneous determination of EN and HCT has been carried by high performance liquid chromatography (HPLC) and by the first- and second-derivative ultraviolet spectrophotometry (Carlucci, Giuseppe, \& Mazzeo, 1993; El Walily, Belal, Heaba, \& El Kersh, 1995; Pawar, Nageswara-Rao, \& Sankar, 2011; Shetkar \& Shinde, 1997; Sowjanya, Gangadhar, Ramalingeswara-Rao, Subrahmanyam, \& Suresh, 2012). While, simultaneous determination of BIS and HCT has been reported using only HPLC methods (Joshi, Karbhari, Bhoir, Bindu, \& Das, 2010; Shaikh et al., 2008).<smiles>CS(=O)(=O)c1cc2c(cc1Cl)NCNS2(=O)=O</smiles>

Hydrochlorothiazide (HCT)<smiles>CCOC(=O)[C@H](CCc1ccccc1)N[C@@H](C)C(=O)N1CCC[C@H]1C(=O)O</smiles>

Enalapril (EN)<smiles>CC(C)NC[C@H](O)COc1ccc(COCCOC(C)C)cc1</smiles>

Bisoprolol (BIS)

Figure 1. Schematic chemical structure of hydrochlorothiazide (HCT), enalapril (EN), and bisoprolol (BIS) 
The bivariate calibration spectrophotometric method is simple and reliable method for estimation and resolution of binary mixtures, since it works to produce optimal wavelengths for severely overlapped absorption spectra of binary mixtures. This property is considered the main advantage of the bivariate calibration method over the derivative spectrophotometric and HPLC methods (Dinç \& Üstündağ, 2005; Hoizey et al., 2002; Karpińska, Sokół, \& Skoczylas, 2008; Laud, Pednekar, Vaidya, Joshi, \& Parekh, 2009; López-Martíneza, López-de-Albab, \& Cerdá-Martín, 2001; Metwally, 2008; Salama, Nassar, Sharaf El-Din, Attia, \& Yousri, 2011; Vujić, Crevar, Obradović, Kuntić, \& Uskoković-Marković, 2009).

The objective of this work is to investigate the feasibility of the bivariate calibration method to provide optimal wavelengths that could be used for the simultaneous determination of EN Maleate/HCT and BIS fumarate/HCT in pharmaceutical binary mixtures with good accuracy and precision of the results.

\section{Experimental}

\subsection{Bivariate Method}

\subsubsection{Instrument}

A Shimadzu (UV-1800) spectrophotometer (Japan) for UV-vis measurements using 1-cm quartz cuvette. The spectrophotometer is connected to an HP Compaq computer, the data analyses are carried out using UV-probe 2.33 software.

\subsubsection{Materials, Chemicals and Reagents}

HCT (purity, 99.2\%) is kindly provided by Unichem Laboratories Limited (India), Batch No. ROHCT/g0414. BIS Fumarate (purity, 98.1\%) is supplied by Unichem Laboratories Limited (India), Batch No. ROBFU/g0305. EN (purity, 98.5\%) is supplied by Jordan-Sweedan Medical and Sterilization Co., Batch No. EM10305005. The commercial mixture of HCT and EN Maleate drug $\left(\right.$ Anjozide $^{\circledR}$ ) is available as tablets at $12.5 \mathrm{mg}$ HCT and $20 \mathrm{mg}$ EN Maleate. The Anjozide ${ }^{\circledR}$ tablet is manufactured by the Jordanian Pharmaceutical Manufacturing Co., Batch No. 110401. The commercial mixture of HCT and BIS Fumarate drug $\left(\mathrm{Ziac}^{\circledR}\right)$ is available as tablets at $6.25 \mathrm{mg}$ HCT and $10 \mathrm{mg}$ BIS Fumarate. Ziac ${ }^{\circledR}$ tablet is manufactured by Watson Pharmaceuticals, Inc., USA. All solutions were prepared using analytical-reagent grade chemicals. Doubly distilled water was used to prepare the stock and working solutions.

\subsubsection{Preparation of Standards}

$500 \mathrm{mg} / \mathrm{L}$ stock solutions of HCT, EN, and BIS Fumarate were prepared in methanol/water (10:90, v/v) solutions. Working solutions in the range of 10 to $50 \mathrm{mg} / \mathrm{L} \mathrm{HCT}, 10$ to $50 \mathrm{mg} / \mathrm{L} \mathrm{EN}$, and 20 to $100 \mathrm{mg} / \mathrm{L}$ BIS Fumarate were prepared to construct the calibration curves. Several mixtures of HCT/EN and HCT/BIS Fumarate were prepared in the methanol/water solutions.

The stock of drug samples were prepared by crushing several tablets from each drug to powder, then accurately weighed powders were dissolved in $20 \mathrm{ml}$ methanol/water $(10: 90, \mathrm{v} / \mathrm{v})$ solution and sonicated for 10 minutes to dissolve the drug before the solutions were filtered using 0.45 micron Whatman filter paper to remove insoluble additives, and after that the mixtures dissolved drugs were diluted in $100 \mathrm{ml}$ volumetric flasks. Several concentrations of each drug were prepared by the step dilution procedure.

\subsection{Liquid Chromatography Method}

\subsubsection{Instrument}

Integrated HPLC system from Shimadzu Corporation (Chromatographic and Spectrophotometric Division, Kyoto, Japan) was used. The system consisted of a LC 20AT pump, column, and a SPD-M20A detector. The chromatograms were recorded and integrated on PC installed with LC solution chromatographic software, version 1.22 SP1 (Shimadzu, Kyoto, Japan).

\subsubsection{Reagents and Chromatographic Conditions}

All solutions were prepared using HPLC grade solvents. Doubly distilled water was used to stock and working solutions. The chromatographic separations were carried out on a C-18 TRACER EXTRASIL ODS $15 \mu \mathrm{m} 25 \times$ 0.46. Chromatographic conditions: (1) Analysis of the mixture of HCT/EN were set using the method by El Walily et al. (1995), in which the flow rate, $1.0 \mathrm{~mL} \mathrm{~min}^{-1}$; wavelength at 215 for $3.5 \mathrm{~min}$, and then changed to $275 \mathrm{~nm}$; Mobile phase: acetonirtile-water $(20: 80, \mathrm{v} / \mathrm{v})$ with $\mathrm{pH}=2.8$; (2) Analysis of the mixture of HCT/BIS Fumarate were set using the method that proposed by Joshi et al. (2010), in which the flow rate, $1.0 \mathrm{~mL} \mathrm{~min}^{-1}$; wavelength at $228 \mathrm{~nm}$; Mobile phase: $0.10 \mathrm{M}$ potassium dihydrogen phosphate buffer and acetonitrile (70:30, $\mathrm{v} / \mathrm{v})$. 


\subsubsection{Sample Preparation and Procedures}

Samples were dissolved using the mobile phases; filtered through an HPLC filter. Peak areas were used for quantification based on caffeine as an internal standard. The Caffeine is used in this study since it has similar chemical properties to the analyzed components of drugs and its chemistry is well established in the literature (Walily et al., 1995). The whole analysis was done using two working standard preparation; first standard was injected 6 times while the other injected twice; the standard deviation for six injection were less that $1 \%$ that indicates the stability of the HPLC over the analysis time, while the difference between the two standards was less than $2 \%$ that ruling out the possibility of personal errors. Reported numbers are average of four replicates and each replicate was injected twice.

\section{Results and Discussion}

\subsection{The Bivariate Method}

The analysis of a two-component mixture $(\mathrm{AB})$ can be performed using the absorption method (Deming, Michotte, Massart, Kaufman, \& Vandeginste, 1988; López-Martíneza et al., 2001; Metwally, 2008). The absorption method is based on the additive absorbance of the two components in the mixture at a certain wavelength, which can be described by the following expression:

$$
A_{\mathrm{AB}}=\varepsilon_{\mathrm{A}} b C_{\mathrm{A}}+\varepsilon_{\mathrm{B}} b C_{\mathrm{B}}
$$

Where $A_{\mathrm{AB}}$ is the absorbance of the two components $\mathrm{A}$ and $\mathrm{B}$ in the mixture; $b$ is the optical path length $(1 \mathrm{~cm})$; $\varepsilon_{\mathrm{A}}, \varepsilon_{\mathrm{B}}$ are the molar absorptivity coefficients of the two components in the mixture at a certain wavelength; $C_{\mathrm{A}}$, $C_{\mathrm{B}}$ are the concentrations of $\mathrm{A}$ and $\mathrm{B}$ in the mixture. The concentrations of the two components in mixture can be determined through two sets of absorbance measurements at two different wavelengths, The two optimal wavelengths can be chosen by applying the bivariate calibration procedure which was proposed by Deming et al. (1988), the procedure consists of resolving the determinant of selectivity $(\mathrm{m}=\varepsilon b)$ matrix $(\mathrm{K})$ :

$$
\mathbf{K}=\left(\begin{array}{ll}
m_{A 1} & m_{B 1} \\
m_{A 2} & m_{B 2}
\end{array}\right)
$$

where $m_{\mathrm{A} 1}, m_{\mathrm{A} 2}$ represents the selectivity parameters of component $\mathrm{A}$ at the two selected wavelength $\left(\lambda_{1}\right.$ and $\left.\lambda_{2}\right)$ and $m_{\mathrm{B} 1}, m_{\mathrm{B} 2}$ correspond to the selectivity parameters of component $\mathrm{B}$. In this case the selectivity parameters are considered as the calibration curve slopes for each component at the two selected wavelengths. The absorption values of mixtures at the two selected wavelengths were used for simultaneous determinations of individual components in the mixtures Deming et al. (1988).

\subsubsection{Hydrochlorothiazide/Enalapril Maleate Mixture}

The bivariate calibration method is applied to the mixture of HCT/EN. Figure 1 shows the absorption spectra of $\mathrm{HCT}$ and $\mathrm{EN}$ at $10 \mathrm{ppm}$ each in methanol/water $(10: 90, \mathrm{v} / \mathrm{v})$.

HCT shows three maximum absorbances at wavelengths of 226, 272, and $320 \mathrm{~nm}$, while Enalapril shows a maximum absorbance at a wavelength of $207 \mathrm{~nm}$. The absorption spectrum of the mixture shows an spectral overlapping in the region between $200-240 \mathrm{~nm}$. The absorption in this region is resulted from $\pi \rightarrow \pi^{*}$ transitions in both compounds. 


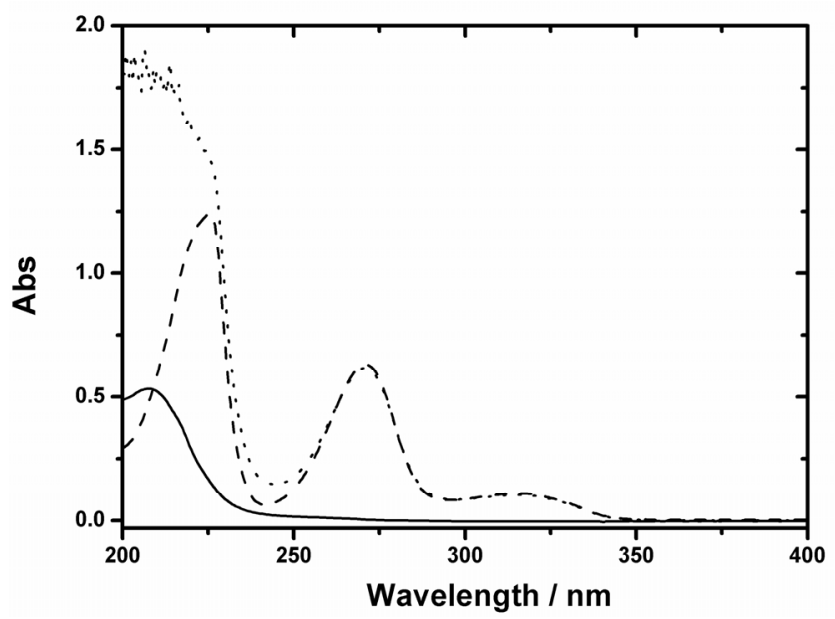

Figure 2. UV-vis spectra of EN (-), HCT (-----), and a mixture of EN/HCT at a concentration of $10 \mathrm{ppm}$

In order determine the concentration of each component in the mixture; the signals of the two components were measured at selected seven wavelengths: 211, 234, 242, 252, 272, 292, and $315 \mathrm{~nm}$. The values of slopes obtained for each component represent the sensitivity values. Those sensitivity values for each wavelength pair was defined by resolving the determinants of the selectivity (K), Table 1 . The optimal wavelength pairs with the highest absolute sensitivity values for HCT/EN were 211 and $272 \mathrm{~nm}$ (Table 1). The linearity was obtained for hydrochlorothiazide in the concentration range 10 to $50 \mathrm{mg} / \mathrm{L}$ and enalapril maleate in the concentration range 10 to $50 \mathrm{mg} / \mathrm{L}$. The linear calibration equations used for the mixture are presented in Table 2 the slopes of these equations were used for direct determinations of the drug tablet.

Table 1 . The values of the absolute selectivity of Kaiser's Determinant $\left(\mathrm{K} \times 10^{5}\right)$ for HCT/EN mixture

\begin{tabular}{cccccccc}
\hline$\lambda_{1} / \lambda_{2}(\mathrm{~nm})$ & 211 & 234 & 242 & 254 & 272 & 292 & 315 \\
\hline 211 & - & 176.67 & 10.45 & 77.85 & $\mathbf{3 6 9 . 8 6}$ & 49.54 & 64.53 \\
234 & - & - & 10.97 & 3.623 & 54.12 & 6.033 & 9.606 \\
242 & - & - & - & 5.095 & 26.09 & 3.432 & 4.574 \\
254 & - & - & - & - & 16.33 & 1.649 & 2.918 \\
272 & - & - & - & - & - & 2.584 & 0.2826 \\
292 & - & - & - & - & - & - & 0.4915 \\
315 & - & - & - & - & - & - & - \\
\hline
\end{tabular}

Table 2. Linear calibration equations for HCT/EN mixture used for the bivariate method

\begin{tabular}{lccc}
\hline Mixture & Components & \multicolumn{2}{c}{ Calibration Equations } \\
\cline { 3 - 4 } & & \multicolumn{2}{c}{$\lambda_{1}=211 \mathrm{~nm}$} \\
\hline HCT/EN & HCT/EN & $\mathrm{Y}=0.0661 \mathrm{X}-0.2591 \mathrm{r}^{2}=0.9999$ & $\mathrm{Y}=0.0643 \mathrm{X}-0.1142 \mathrm{r}^{2}=0.9985$ \\
& & $\mathrm{Y}=0.0588 \mathrm{X}-0.0604 \mathrm{r}^{2}=0.9999$ & $\mathrm{Y}=0.0014 \mathrm{X}-0.0087 \mathrm{r}^{2}=0.9982$ \\
\hline
\end{tabular}

$\mathrm{Y}$ is the absorbance values at selected wavelength; $\mathrm{X}$ is the concentrations in ppm. $\mathrm{r}^{2}$ is the coefficient of determination.

The applicability of the proposed wavelength pairs to a routine analysis was applied by analyzing laboratory prepared mixtures, in which the concentration ratios of HCT to EN were in the range 1:5 to 5:1 by adjusting their concentrations in the mixtures. A selected set of prepared mixtures and the percentage recoveries are presented in 
Table 3. The results of the analysis in Table 3 appear to be quite independent of the concentration ratios of the components in the mixtures. The analysis of a commercially available pharmaceutical drug $\left(\right.$ Angiozid $\left.^{\mathbb{B}}\right)$ and the percentage recoveries of the drug were calculated and given in Table 4.

Table 3. Determination of HCT/EN in selected sets of laboratory prepared mixtures by the proposed methods

\begin{tabular}{ccccccc}
\hline \multirow{2}{*}{ Mixture } & \multicolumn{3}{c}{ HCT } & \multicolumn{3}{c}{ EN } \\
\cline { 2 - 7 } & $\begin{array}{c}\text { Concentration } \\
(\mathrm{mg} / \mathrm{L})\end{array}$ & $\begin{array}{c}\text { Found } \\
(\mathrm{mg} / \mathrm{L})\end{array}$ & $\%$ Recovery \pm S.D. & $\begin{array}{c}\text { Concentration } \\
(\mathrm{mg} / \mathrm{L})\end{array}$ & $\begin{array}{c}\text { Found } \\
(\mathrm{mg} / \mathrm{L})\end{array}$ \\
\hline $1(1: 1)$ & 50 & 49.6 & 99.4 & 50 & 50.2 & 100.6 \\
$2(1: 5)$ & 10 & 9.9 & 99.0 & 50 & 48.3 & 96.6 \\
$3(5: 1)$ & 50 & 50.1 & 100.2 & 10 & 9.4 & 94.0 \\
Mean \pm S.D. & & & $99.5 \pm 0.61$ & & & $97.1 \pm 3.32$ \\
\hline
\end{tabular}

${ }^{\text {a }}$ Standard Deviation.

Table 4. Analysis of HCT/EN in a commercially available pharmaceutical drug

\begin{tabular}{|c|c|c|c|c|c|c|}
\hline \multirow[t]{3}{*}{ Drug } & \multirow{2}{*}{\multicolumn{2}{|c|}{$\begin{array}{l}\text { Label Claim } \\
\quad(\mathrm{mg} / \mathrm{L})\end{array}$}} & \multicolumn{4}{|c|}{$\%$ Recoveries \pm S.D. } \\
\hline & & & \multicolumn{2}{|c|}{ Bivariate Method $^{\mathrm{a}}$} & \multicolumn{2}{|c|}{ HPLC $^{\mathrm{b}}$} \\
\hline & HCT & EN & HCT & EN & $\mathrm{HCT}$ & EN \\
\hline & & Maleate & & Maleate & & Maleate \\
\hline Angiozid $\AA$ & 12.5 & 20 & $97.5 \pm 2.18$ & $98.7 \pm 1.59$ & $96.9 \pm 2.31$ & $99.6 \pm 0.84$ \\
\hline
\end{tabular}

${ }^{\text {a }}$ average of five determinations.

${ }^{\mathrm{b}}$ average of four determinations.

\subsubsection{Hydrochlorothiazide/Bisoprolol Fumarate Mixtures}

The absorption spectra of hydrochlorothiazide and bisoprolol fumarate are shown in Figure 3. Bisoprolol shows two maximum absorbances at wavelengths of 226 and $272 \mathrm{~nm}$, which are in complete overlapping with the first two bands of HCT as shown the absorption spectrum of the mixture. The bivariate method was applied on this mixture, the signal at seven wavelengths were measured at 226, 242, 253.5, 264, 270.5, 273.5, and 293. The analysis of $(\mathrm{K})$ determinant showed that the wavelength pairs with highest absolute sensitivity were 273.5 and $293 \mathrm{~nm}$ (Table 5).

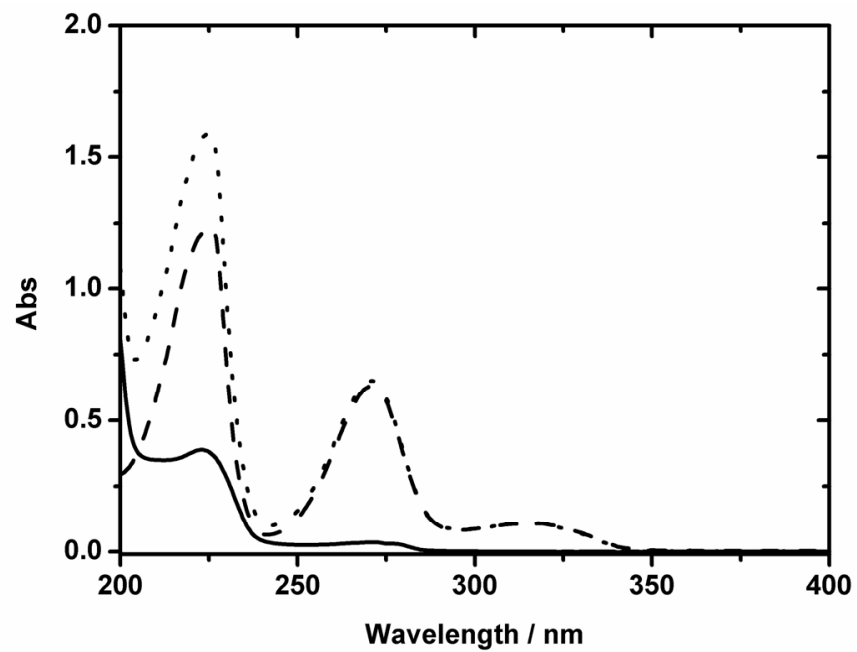

Figure 3. UV-vis spectra of BIS fumarate (-) at a concentration of $30 \mathrm{ppm}, \mathrm{HCT}(-----)$ at a concentration of 10 $\mathrm{ppm}$, and a mixture of HCT/ BIS fumarate 
Table 5. The values of the absolute selectivity of Kaiser's Determinant $\left(\mathrm{K} \times 10^{5}\right)$ for HCT/BIS fumarate mixture

\begin{tabular}{cccccccc}
\hline$\lambda_{1} / \lambda_{2}(\mathrm{~nm})$ & 226 & 242 & 253.5 & 264 & 270.3 & 273.5 & 293 \\
\hline 226 & - & 87.044 & 16.006 & 10.965 & 34.811 & 31.143 & 9.651 \\
242 & - & - & 108.385 & 67.265 & 117.509 & 118.921 & 62.977 \\
253.5 & - & - & - & 1.284 & 21.370 & 16.912 & 38.918 \\
264 & - & - & - & - & 11.185 & 9.085 & 24.899 \\
270.5 & - & - & - & - & - & 41.158 & 55.329 \\
273.5 & - & - & - & - & - & - & $\mathbf{1 5 2 . 7 6 2}$ \\
293 & - & - & - & - & - & - & - \\
\hline
\end{tabular}

Table 6 shows the calibration equations of the mixture at the proposed wavelengths. These wavelengths were applied in the analysis of HCT and BIS Fumarate in different concentration ratios of laboratory prepared mixtures. Results of the percentage recoveries are shown in Table 7, which suggested that method was accurate for the simultaneous estimation of HCT and BIS Fumarate from their combination mixtures. The method was applied for the analysis of one marketed drug $\left(\mathrm{Ziac}^{\mathbb{B}}\right)$ containing BIS Fumarate $10 \mathrm{mg}$ and HCT $6.25 \mathrm{mg}$ per tablet. The results of the analysis are given in Table 8.

Table 6. Linear calibration equations of HCT/BIS fumarate used for the bivariate method

\begin{tabular}{lccc}
\hline \multirow{2}{*}{ Mixture } & \multirow{2}{*}{ Components } & \multicolumn{2}{c}{ Calibration Equations } \\
\cline { 3 - 4 } & & $\lambda_{1}=273.5 \mathrm{~nm}$ & $\lambda_{2}=293 \mathrm{~nm}$ \\
\hline HCT/BIS & HCT $/ \mathrm{BIS}$ & $\mathrm{Y}=0.0832 \mathrm{X}-0.0149 \mathrm{r}^{2}=0.9987$ & $\mathrm{Y}=0.0337 \mathrm{X}-0.2254 \mathrm{r}^{2}=0.9886$ \\
Fumarate & Fumarate & $\mathrm{Y}=0.0172 \mathrm{X}-0.1019 \mathrm{r}^{2}=0.9997$ & $\mathrm{Y}=0.0007 \mathrm{X}-0.0261 \mathrm{r}^{2}=0.9821$ \\
\hline
\end{tabular}

$\mathrm{Y}$ is the absorbance values at selected wavelength; $\mathrm{X}$ is the concentrations in ppm. $\mathrm{r}^{2}$ is the coefficient of determination.

Table 7. Determination of HCT/BIS Fumarate in selected sets of laboratory prepared mixtures by the proposed methods

\begin{tabular}{ccccccc}
\hline Mixture & \multicolumn{3}{c}{ HCT } & \multicolumn{3}{c}{ BIS Fumarate } \\
\hline & $\begin{array}{c}\text { Concentration } \\
(\mathrm{mg} / \mathrm{L})\end{array}$ & $\begin{array}{c}\text { Found } \\
(\mathrm{mg} / \mathrm{L})\end{array}$ & \%Recovery \pm S.D. & $\begin{array}{c}\text { Concentration } \\
(\mathrm{mg} / \mathrm{L})\end{array}$ & $\begin{array}{c}\text { Found } \\
(\mathrm{mg} / \mathrm{L})\end{array}$ & \% Recovery \pm S.D. \\
\cline { 2 - 7 } $1(1: 1)$ & 50 & 50.2 & 100.9 & 50 & 47.2 & 94.4 \\
$2(1: 5)$ & 10 & 9.8 & 98.0 & 50 & 48.5 & 97.0 \\
$3(5: 1)$ & 50 & 49.9 & 99.8 & 10 & 9.7 & 97.0 \\
Mean \pm S.D. & & & $99.6 \pm 1.46$ & & & $96.1 \pm 1.50$ \\
\hline
\end{tabular}

Table 8. Analysis of HCT/BIS Fumarate in a commercially available pharmaceutical drug

\begin{tabular}{|c|c|c|c|c|c|c|}
\hline \multirow[t]{3}{*}{ Drug } & \multicolumn{2}{|c|}{ Label Claim (mg/L) } & \multicolumn{4}{|c|}{$\%$ Recoveries \pm S.D. } \\
\hline & & & \multicolumn{2}{|c|}{ Bivariate Method $^{\mathrm{a}}$} & \multicolumn{2}{|c|}{ HPLC $^{b}$} \\
\hline & HCT & BIS fumarate & $\mathrm{HCT}$ & BIS fumarate & HCT & BIS fumarate \\
\hline $\operatorname{Ziac}^{\circledR}$ & 6.25 & 10 & $98.2 \pm 1.41$ & $98.1 \pm 0.99$ & $97.8 \pm 1.81$ & $98.8 \pm 1.67$ \\
\hline
\end{tabular}




\subsection{The HPLC Methods}

The revered-phase HPLC methods were used to confirm the results of analysis of bivariate method. Angiozide ${ }^{\circledR}$ which contains HCT/EN meleate was analyzed using the method El Walily et al. (1995), which involves use a C-18 column and mobile phase consisting of acetonitrile/water $(20: 80, \mathrm{v} / \mathrm{v})(\mathrm{pH}=3.8)$. The wavelengths of detection were changed during the run to achieve maximum responses for the HCT and EN meleate in the drug sample. The chromatographic analysis of Angiozide ${ }^{\circledR}$ sample showed a good resolution of HCT and EN meleate. The order of elution of the Angiozide ${ }^{\circledR}$ sample was EN meleate $\left(t_{r}=2.91 \mathrm{~min}\right)$, Caffeine $\left(t_{r}=5.70 \mathrm{~min}\right)$ (the internal standard), and HCT $\left(t_{r}=7.56 \mathrm{~min}\right)$ at a flow rate of $1.0 \mathrm{~mL} / \mathrm{min}$. The chromatogram of the sample also showed the appearance of a few unidentified peaks which may be contributed to the presence of soluble additives in the sample. The results of this analysis are given in Table 4. Similarly, Ziac ${ }^{\mathbb{B}}$ which contains HCT/BIS fumarate was analyzed using method by Joshi et al. (2010), The retention times were 7.56 min BIS fumarate, $5.74 \mathrm{~min}$ for Caffeine, and $6.81 \mathrm{~min}$ for HCT. The results of $\mathrm{Ziac}^{\circledR}$ analysis are given in Table 8 .

\subsection{Statistical Analysis of the Results}

The results obtained for the HCT/EN Maleate and HCT/BIS Fumarate in the pharmaceutical tablets in Tables 4 and 8 were statistically compared using Student's $t$-test and the variance ratio $F$-test, the results are given in Table 9 and Table 10.

Table 9. Statistical analysis of the results obtained by Bivariate method and the HPLC for Angiozide ${ }^{\circledR}$

\begin{tabular}{ccccc}
\hline \multirow{2}{*}{ Parameters } & \multicolumn{2}{c}{ Bivariate Method } & \multicolumn{2}{c}{ HPLC } \\
\cline { 2 - 5 } & HCT & EN Maleate & HCT & EN Maleate \\
\hline Mean \pm S.D. & $97.5 \pm 2.18$ & $98.7 \pm 1.59$ & $96.9 \pm 2.31$ & $99.6 \pm 0.84$ \\
$N$ & 5 & 5 & 4 & 4 \\
Variance & 4.752 & 2.528 & 5.336 & 0.706 \\
$t(2.37)^{*}$ & 0.402 & 1.015 & - & - \\
$F(5.19)^{*}$ & 1.123 & 3.581 & - & - \\
\hline
\end{tabular}

* The values in parentheses are corresponding to the theoretical values of $t$ and $F$ at $(p=0.05)$.

Table 10. Statistical analysis of the results obtained by Bivariate method and the HPLC for Ziac ${ }^{\circledR}$

\begin{tabular}{ccccc}
\hline \multirow{2}{*}{ Parameters } & \multicolumn{3}{c}{ Bivariate Method } & \multicolumn{2}{c}{ HPLC } \\
\cline { 2 - 5 } & HCT & BIS fumarate & HCT & BIS fumarate \\
\hline Mean \pm S.D. & $98.2 \pm 1.41$ & $98.1 \pm 0.99$ & $97.8 \pm 1.81$ & $98.8 \pm 1.67$ \\
$N$ & 5 & 5 & 4 & 4 \\
Variance & 1.988 & 0.980 & 3.276 & 2.789 \\
$t(2.37)^{*}$ & 0.374 & 0.788 & - & - \\
$F(5.19)^{*}$ & 1.648 & 2.846 & - & - \\
\hline
\end{tabular}

* The values in parentheses are corresponding to the theoretical values of $t$ and $F$ at $(p=0.05)$.

The Statistical analysis showed that there is no significant difference between the proposed bivariate methods and the HPLC methods, as well as the there is no significant difference between the precision of proposed method and the HPLC methods.

The closeness of the results obtained in pharmaceutical tablets to the label claim supports the accuracy of the used method. It was notice that the accuracy of the pharmaceutical mixtures was different from the claim labels, this may be attributed to the matrix effect since it is accustomed to use insoluble additives in pharmaceutical tablets which is used to hold the structure of tablets.

\section{Conclusion}

The bivariate method was applied for determining the hydrochlorothiazide/enalapril maleate and hydrochlorothiazide/bisoprolol fumarate in pharmaceutical tablets. The proposed method is simple, time saving, 
and does not need any sophisticated apparatus. The samples were also analyzed by standard HPLC methods, the results are in excellent agreement with those obtained by the bivariate method.

\section{Acknowledgements}

The authors wish to acknowledge the financial support of The Tafila Technical University (Grant number 176/2008).

\section{References}

Carlucci, G., Giuseppe, E. D., \& Mazzeo, P. (1993). Simultaneous determination of enalapril maleate and hydrochlorothiazide in tablets by derivative UV spectrophotometry and high-performance liquid

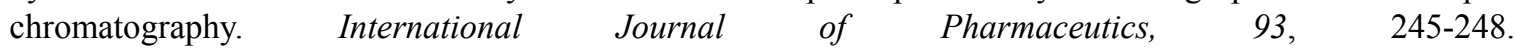
http://dx.doi.org/10.1016/0378-5173(93)90184-H

Deming, S. N., Michotte, Y., Massart, D. L., Kaufman, L., \& Vandeginste, B. G. M. (1988). Chemometrics: a Textbook (1st ed.). Amsterdam: Elsevier.

Dinç, E., \& Üstündağ, Ö. (2005). Application of Multivariate Calibration Techniques to HPLC Data for Quantitative Analysis of a Binary Mixture of Hydrochlorathiazide and Losartan in Tablets. Chromatographia, 61(5-6), 237-244. http://dx.doi.org/10.1365/s10337-005-0511-1

El Walily, A. F., Belal, S. F., Heaba, E. A., \& El Kersh, A. (1995). Simultaneous determination of enalapril maleate and hydrochlorothiazide by first-derivative ultraviolet spectrophotometry and high-performance liquid chromatography. J. Pharm. Biomed. Anal., 13, 851-856. http://dx.doi.org/10.1016/0731-7085(95)01346-M

Hoizey, G., Lamiable, D., Frances, C., Trenque, T., Kaltenbach, M., Denis, J., \& Millart, H. (2002). Simultaneous determination of amoxicillin and clavulanic acid in human plasma by HPLC with UV detection. J. Pharm Biomed Anal., 30, 661-666. http://dx.doi.org/10.1016/S0731-7085(02)00289-3

Joshi, S. J., Karbhari, P. A., Bhoir, S. I., Bindu, K. S., \& Das, C. (2010). RP-HPLC method for simultaneous estimation of bisoprolol fumarate and hydrochlorothiazide in tablet formulation. J. Pharm. Biomed. Anal., 52, 362-371.http://dx.doi.org/10.1016/j.jpba.2009.10.021

Karpińska, J., Sokół, A., \& Skoczylas, M. (2008). An application of UV-derivative spectrophotometry and bivariate calibration algorithm for study of photostability of levomepromazine hydrochloride. Spectrochim. Acta Part A, 71, 1562-1564. http://dx.doi.org/10.1016/j.saa.2008.06.007

Laud, A. J., Pednekar, S., Vaidya, V. V., Joshi, S. S., \& Parekh, S. A. (2009). Simultaneous Estimation Of Anti-Hypertensive Drugs And A Vitamin In A Pharmaceutical Formulation. Anal. Chem.: An Indian J., 8(4), 479-488.

López-Martíneza, L., López-de-Albab, P. L., \& Cerdá-Martín, V. (2001). Bivariate calibration as an alternative for zero-crossing technique in the resolution of binary mixtures by derivative spectrophotometry. Anal. lett., 34(14), 2563-2583. http://dx.doi.org/10.1081/AL-100107536

Metwally, F. H. (2008). Simultaneous determination of nifuroxazide and drotaverine hydrochloride in pharmaceutical preparations by bivariate and multivariate spectral analysis. Spectrochim. Acta Part A, 69, 343-349. http://dx.doi.org/10.1016/j.saa.2007.04.004

Pawar, A. K. M., Nageswara-Rao, A. B. N., \& Sankar, D. G. (2011). Simultaneous Estimation of Enalapril Maleate, Hydrochlorothiazide, Aspirin and Atorvastatin in pure and Its Simulated Dosage form Using Isocratic RP-HPLC. Der Pharmacia Lettre, 3(6), 58-67.

Salama, F. M. M., Nassar, M. W. I., Sharaf El-Din, M. M. K., Attia, K. A. M., \& Yousri, K. M. (2011). Determination of Fenofibrate and the Degradation Product Using Simultaneous UV-Derivative Spectrometric Method and HPLC. American Journal of Analytical Chemistry, 2, 332-343. http://dx.doi.org/10.4236/ajac.2011.23041

Shaikh, S., Thusleema, O. A., Muneeraa, M. S., Akmala, J., Kondagulia, A. V., \& Ruckmanib, K. (2008). A simple and rapid high-performance liquid chromatographic method for the determination of bisoprolol fumarate and hydrochlorothiazide in a tablet dosage form. J. Pharm. Biomed. Anal., 48, 1055-1057. http://dx.doi.org/10.1016/j.jpba.2008.08.009

Shetkar, P. B., \& Shinde, V. M. (1997). Simultaneous determination of enalapril maleate and hydrochlorothiazide in tablets by reversed phase HPLC. Anal. Lett., 30(6), 1143-1152. http://dx.doi.org/10.1080/00032719708004044 
Sowjanya, G., Gangadhar, P., Ramalingeswara-Rao, P., Subrahmanyam, P., \& Suresh, P. (2012). Simultaneous UV spectrphotometric estimation of enalapril maleate and hydrochlorothiazide in tablets. J. Chemical and Pharm. Res., 4(7), 3483-3488.

Vujić, Z., Crevar, M., Obradović, V., Kuntić, V., \& Uskoković-Marković, S. (2009). Simultaneous Determination of Hydrochlorothiazide, Cilazapril and Its Active Metabolite Cilazaprilat in Urine by Gradient RP-LC. Chromatographia, 70(7), 1221-1225. http://dx.doi.org/10.1365/s10337-009-1286-6 